University of Nebraska - Lincoln

DigitalCommons@University of Nebraska - Lincoln

2013

\title{
Afraid to Help: Social Anxiety Partially Mediates the Association between 5-HTTLPR Triallelic Genotype and Prosocial Behavior
}

\author{
Scott F. Stoltenberg \\ University of Nebraska-Lincoln, sstoltenberg2@unl.edu \\ Christa C. Christ \\ University of Nebraska-Lincoln \\ Gustavo Carlo \\ University of Missouri, Columbia, carlog@missouri.edu
}

Follow this and additional works at: https://digitalcommons.unl.edu/psychfacpub

Part of the Genetics Commons, and the Psychology Commons

Stoltenberg, Scott F.; Christ, Christa C.; and Carlo, Gustavo, "Afraid to Help: Social Anxiety Partially Mediates the Association between 5-HTTLPR Triallelic Genotype and Prosocial Behavior" (2013). Faculty Publications, Department of Psychology. 996.

https://digitalcommons.unl.edu/psychfacpub/996

This Article is brought to you for free and open access by the Psychology, Department of at DigitalCommons@University of Nebraska - Lincoln. It has been accepted for inclusion in Faculty Publications, Department of Psychology by an authorized administrator of DigitalCommons@University of Nebraska - Lincoln. 
Published in Social Neuroscience 8:5 (2013), pp. 400-406; doi: 10.1080/17470919.2013.807874

Copyright (C) 2013 Taylor \& Francis. Used by permission.

Submitted December 14, 2012; revised May 17, 2013; published online June 21, 2013.

Supplemental tables follow the references.

\title{
Afraid to Help: Social Anxiety Partially Mediates the Association between 5-HTTLPR Triallelic Genotype and Prosocial Behavior
}

\author{
Scott F. Stoltenberg, ${ }^{1}$ Christa C. Christ, ${ }^{1}$ and Gustavo Carlo ${ }^{2}$
}

1. Department of Psychology, University of Nebraska-Lincoln, Lincoln, USA

2. Department of Human Development and Family Studies, University of Missouri, Columbia, USA

Corresponding author - Scott F. Stoltenberg, 238 Burnett Hall, University of Nebraska, Lincoln, NE 68588, USA, email sstoltenberg2@unl.edu

\begin{abstract}
There is growing evidence that the serotonin system influences prosocial behavior. We examined whether anxiety mediated the association between variation in the serotonin transporter gene regulatory region (5-HTTLPR) and prosocial behavior. We collected self-reported tendencies to avoid certain situations and history of helping others using standard instruments and buccal cells for standard 5-HTTLPR genotyping from 398 undergraduate students. Triallelic 5-HTTLPR genotype was significantly associated with prosocial behavior and the effect was partially mediated by social anxiety, such that those carrying the $S^{\prime}$ allele reported higher levels of social avoidance and lower rates of helping others. These results are consistent with accounts of the role of serotonin on anxiety and prosocial behavior and suggest that targeted efforts to reduce social anxiety in $\mathrm{S}^{\prime}$ allele carriers may enhance prosocial behavior.
\end{abstract}

Keywords: avoidance, rs25531, SLC6A4, altruism, behavioral inhibition

In the present study, we tested whether anxiety mediates the association between a common genetic polymorphism in the serotonin $(5-\mathrm{HT})$ neurotransmitter system and prosocial behavior (i.e., committing voluntary acts with the intention of benefiting others; see 
Eisenberg, Fabes, \& Spinrad, 2006). There is evidence that individual differences in propensity to act prosocially are due, at least in part, to genetic differences and that genes also contribute to the stability of the trait over time (Gregory, Light-Hausermann, Rijsdijk, \& Eley, 2009). However, the specific genes that influence prosocial behavior have not yet been identified and the mechanisms by which they influence prosocial behavior are not yet fully characterized. There are many levels of analysis between DNA sequence and prosocial behavior, which are not customarily considered for the sake of convenience in the standard candidate gene association study approach. However, the vital and arduous tasks of identifying and elucidating mediating pathways from genes to complex behaviors remain. In the context of prosocial behaviors, many psychological constructs (e.g., empathy and moral reasoning) that are potential mediating pathways have been identified (see Carlo, 2006), but little work has been done to explicitly test whether associations between particular genetic polymorphisms and prosocial behaviors are mediated by particular psychological traits.

Recent studies have provided strong evidence that the serotonin (5-HT) neurotransmitter system influences several psychological traits or behaviors relevant to prosocial behavior. Experimentally reduced levels of central 5-HT via acute tryptophan depletion slow the acquisition of cooperative behavior (Wood, Rilling, Sanfey, Bhagwagar, \& Rogers, 2006), increase retaliation to perceived unfairness (Crockett, 2009), reduce reflexive avoidance of punishment (Crockett, Clark, \& Robbins, 2009), and reduce neural activity and representation of reward outcome (Seymour, Daw, Roiser, Dayan, \& Dolan, 2012). Increasing 5-HT availability via selective serotonin reuptake treatment increased the likelihood that emotionally salient actions harmful to others were judged to be forbidden (Crockett, Clark, Hauser, \& Robbins, 2010). The results of these studies suggest that genetic variation that affects 5-HT availability may influence prosocial behavior.

A well-studied polymorphism (5-HTTLPR; see Murphy et al., 2008) in the regulatory region of gene that codes for the 5-HT transporter (SLC6A4) exerts some measure of control over 5-HT availability and therefore is a likely candidate for association with prosocial behavior. There is growing evidence that 5-HTTLPR is associated with several behaviors or traits that are relevant in the context of opportunities to act prosocially such as decisionmaking under ambiguity (Stoltenberg, Lehmann, Anderson, Nag, \& Anagnopoulos, 2011), fear conditioning (Crisan et al., 2009), neural activation in fear-related brain areas during fear conditioning (Klucken et al., 2012), loss aversion (He et al., 2010), and utilitarian moral judgments (Marsh et al., 2011). That 5-HT is an important player in modulating propensity to prosocial behavior fits well within the framework of reinforcer sensitivity theory (Corr \& McNaughton, 2012) via behavioral inhibition (Cools, Nakamura, \& Daw, 2011; Dayan \& Huys, 2008). The 5-HT system appears to modulate the processing of aversive stimuli and facilitate behavioral inhibition

Could anxiety mediate the association between 5-HT genetic polymorphisms and prosocial behavior? There is substantial evidence that genetic variation in the 5-HT system is associated with individual differences in anxiety and anxiety-related traits (Hariri \& Holmes, 2006; Leonardo \& Hen, 2006) and that anxiety (as one type of negative emotionality) is generally negatively correlated with prosocial behavior (Eisenberg et al., 2006). To our 
knowledge, this study is the first to directly test the hypothesis that anxiety mediates the association between 5-HTTLPR genotype and prosocial behavior.

\section{Method}

\section{Participants and procedure}

A total of 398 undergraduates (26.5\% men; $89.2 \%$ White; $5.3 \%$ Asian; $4.0 \%$ Black or African American; $0.8 \%$ American Indian/Alaska Native; $0.8 \%$ Native Hawaiian or other Pacific Islander) were recruited from a psychology department's subject pool at a Midwestern University. The mean age was 20.76 years $(S D=3.61)$. Students received course credit for approximately $1 \mathrm{~h}$ of participation. The study was approved by the University's Institutional Review Board and all participants gave written informed consent prior to participating. Participants completed a computerized survey of instruments assessing psychological constructs, behaviors of interest, and demographic items, as well as two computerized behavioral tasks. Participants also donated buccal cells for genotyping. Only data relevant to the present research question will be described here.

\section{Measures}

\section{Trait anxiety}

Trait anxiety was assessed using the adapted Fear Questionnaire (Marks \& Mathews, 1979), consisting of a 9-point scale on which subjects rate how much they would avoid particular situations because of fear or unpleasant feelings (from $0=$ would not avoid it to 8

= always avoid it). The questionnaire consisted of three five-item subscales: total score (Cronbach's $\alpha=.81$ ), agoraphobia (e.g., "large open spaces"; $\alpha=.73$ ), blood injury phobia (e.g., "sight of blood"; $\alpha=.74$ ), and social phobia (e.g., "speaking or acting to an audience"; $\alpha=.60)$.

\section{Prosocial behavior}

Prosocial behavior was assessed using a shortened 14-item measure of helping (Rushton, Chrisjohn, \& Fekken, 1981). These items are rated on a 5-point scale (from $1=$ Never to $5=$ Very Often; Cronbach's $\alpha=.80$ ). Sample items include "I have made change for a stranger" and "I have done volunteer work for a charity."

\section{Approach/avoidance}

The BIS/BAS scale (Carver \& White, 1994) was used to assess motivational systems that may generally underlie behavior. The scale contains three approach-related scales (drive, "When I want something I usually go all-out to get it" [reverse scored], four items $\alpha=.74$; fun seeking, "I crave excitement and new sensations" [reverse scored], four items $\alpha=.64$; reward responsiveness, "When I get something I want, I feel excited and energized" [reverse scored], five items $\alpha=.64$ ) and one avoidance-related scale (behavioral inhibition, "I worry about making mistakes" [reverse scored], seven items $\alpha=.75$ ). All items are rated on a 4 -point scale (from 1 = very true for me to $4=$ very false for me). 


\section{Genotyping}

DNA was extracted from buccal cells using the PURGENE DNA Isolation Kit Protocol (Gentra Systems, Inc., Minneapolis, Minnesota, USA) according to the manufacturer's instructions. Genotypes for 5-HTTLPR and rs25531 were assessed by polymerase chain reaction (PCR) with forward and reverse primers: 5-TCCTCCGCTTTGGCGCCTCTTCC-3' and 5'-TGGGGGTTGCAGGGGAGATCCTG-3' (Wendland, Martin, Kruse, Lesch, \& Murphy, 2006). The PCRs were performed in 25- $\mu$ l reactions containing $20 \mathrm{ng}$ of DNA, 1X GoTaq Master Mix (Promega, Madison, Wisconsin, USA), and $10 \mu \mathrm{M}$ of each primer. The rs25531 polymorphism was recognized by digestion with HpaII with 1X BSA (New England BioLabs, Ipswich, Massachusetts, USA) overnight at $37^{\circ} \mathrm{C}$ using $15 \mu \mathrm{l}$ of the PCR product. Products were separated by electrophoresis on a $2.5 \%$ agarose gel and visualized under UV light with either ethidium bromide or SybrSafe stain. A randomly selected subset of the sample (10\%) was rerun for each polymorphism to check for genotype call discrepancies. No discrepancies were found.

\section{Analyses}

Because of the relatively small number of participants who self-identified as being from racial groups other than White, we were not able to make meaningful statistical comparisons between race groups. Based on the notion that the biological impact of these genetic polymorphisms does not differ among races, race was treated as a statistical covariate (Ioannidis, Ntzani, \& Trikalinos, 2004). Scores for prosocial behavior and for anxiety scales were Winsorized by recoding outliers to the nearest non-outlier score. Association tests were conducted using linear regressions of outcome measures (i.e., prosocial behavior, anxiety scores) on 5-HTTLPR triallelic genotype and covariates (i.e., age, gender [men $=1$, women $=2]$, race $[$ White $=1$; non-White $=2]$ ).

\section{Results}

\section{Descriptive statistics}

The observed frequencies for 5-HTTLPR alleles were $\mathrm{L}=0.56$ and $\mathrm{S}=0.44(\mathrm{~N}=395)$, and the observed genotype frequencies were in Hardy-Weinberg equilibrium $(\mathrm{L} / \mathrm{L}=125, \mathrm{~L} / \mathrm{S}=$ $191, \mathrm{~S} / \mathrm{S}=79 ; \mathrm{df}=1, \chi^{2}=0.15, \mathrm{n} . \mathrm{s}$.). The observed frequencies for rs25531 alleles were $\mathrm{A}=$ 0.92 and $\mathrm{G}=0.08(N=393)$, and the observed genotype frequencies were in Hardy-Weinberg equilibrium $\left(\mathrm{A} / \mathrm{A}=330, \mathrm{~A} / \mathrm{G}=61, \mathrm{G} / \mathrm{G}=2 ; \mathrm{df}=1, \chi^{2}=0.25\right.$, n.s.). Allele frequencies for both polymorphisms were consistent with reports in the literature (Wendland et al., 2006). The observed frequencies for the phase-certain "triallelic" (i.e., 5-HTTLPR and rs25531) genotypes were $L^{\prime} / L^{\prime}=92, L^{\prime} / S^{\prime}=190, S^{\prime} / S^{\prime}=111$, where $L^{\prime}=L_{A}$, and $S^{\prime}=L_{G}$ or $S$.

Descriptive statistics for self-reported prosocial behavior, anxiety subscales, BIS/BAS scales, and zero-order correlations among them are shown in Table 1. Significant negative correlations were observed between prosocial behavior and both agoraphobia and social phobia, whereas the correlation between prosocial behavior and blood/injury phobia score was nonsignificant. This pattern of results indicates that higher levels of certain types of anxiety, but not all, are associated with lower levels of prosocial behavior. Trait anxiety 
about certain social interactions and about being trapped in certain situations or places may reduce likelihood of prosocial behavior, but the fear of bodily harm may not affect propensity for prosocial behavior. Scores for agoraphobia and social phobia are strongly positively correlated, which indicates that these measures are, to some extent, assessing a common construct. Scores on the prosocial behavior scale were significantly positively correlated with all three BAS approach scales and negatively correlated with behavioral inhibition. Drive was not significantly correlated with any of the anxiety scale scores. Fun seeking was significantly negatively correlated with agoraphobia and social anxiety scores. Reward responsiveness was significantly correlated with agoraphobia and blood/injury phobia. Behavioral inhibition was correlated with all three anxiety scales.

Table 1. Descriptive statistics and correlations for prosocial, anxiety, and BIS/BAS variables

\begin{tabular}{|c|c|c|c|c|c|c|c|c|}
\hline \multirow[b]{2}{*}{ Variable } & \multirow[b]{2}{*}{$\mathrm{M}(\mathrm{SD})$} & \multicolumn{7}{|c|}{ Correlations } \\
\hline & & 1 & 2 & 3 & 4 & 5 & 6 & 7 \\
\hline 1. Prosocial behavior & $2.81(0.52)$ & & & & & & & \\
\hline 2. Agoraphobia & $1.53(1.19)$ & $-.204^{* *}$ & & & & & & \\
\hline 3. Blood/injury phobia & $1.97(1.47)$ & -.004 & $.358^{* *}$ & & & & & \\
\hline 4. Social phobia & $2.55(1.25)$ & $-.217^{* *}$ & $.565^{* *}$ & $.316^{* *}$ & & & & \\
\hline 5. Drive & $11.48(2.11)$ & $.174^{* *}$ & -.043 & .040 & -.079 & & & \\
\hline 6. Fun seeking & $12.29(2.00)$ & $.160^{* *}$ & $-.145^{* *}$ & -.045 & $-.126^{*}$ & $.313^{* *}$ & & \\
\hline 7. Reward responsiveness & $18.20(1.67)$ & $.105^{*}$ & $.135^{* *}$ & $.136^{* *}$ & .058 & $.322^{* *}$ & $.298^{* *}$ & \\
\hline 8. Behavioral inhibition & $21.62(3.60)$ & $-.188^{* *}$ & $.335^{* *}$ & $.155^{* *}$ & $.417^{* *}$ & -.057 & $-.124^{*}$ & $.246^{* *}$ \\
\hline
\end{tabular}

Notes: Higher scores on all measures indicate higher levels of the construct. $N=395,{ }^{*} p<.05,{ }^{* *} p<.001$

\section{Regression analyses to test mediation}

We conducted hierarchical multiple regression analyses to test the hypothesis that 5-HTTLPR triallelic genotype ( $\mathrm{L}^{\prime}$ homozygotes versus $\mathrm{S}^{\prime}$ carriers) was associated with prosocial behavior and that the association was mediated by anxiety. 5-HTTLPR triallelic genotype significantly predicted prosocial behavior, $B=0.127, t(388)=2.05, p=.041$ (see Figure 1). 5 -HTTLPR triallelic genotype also predicted agoraphobic anxiety $(B=-0.404, t(391)=-2.95$, $p=.0034)$ and social anxiety scores $(B=-0.476, t(391)=-3.34, p=.0009)$, but not blood/injury phobia scores $(B=-0.026, t(391)=-0.15, p=.881)$. Those carrying one or two $S^{\prime}$ alleles reported significantly higher levels of avoidance behavior than L' homozygotes for situations and places in which they felt trapped (i.e., agoraphobia) and for social situations (i.e., social phobia; see Figure 2). 


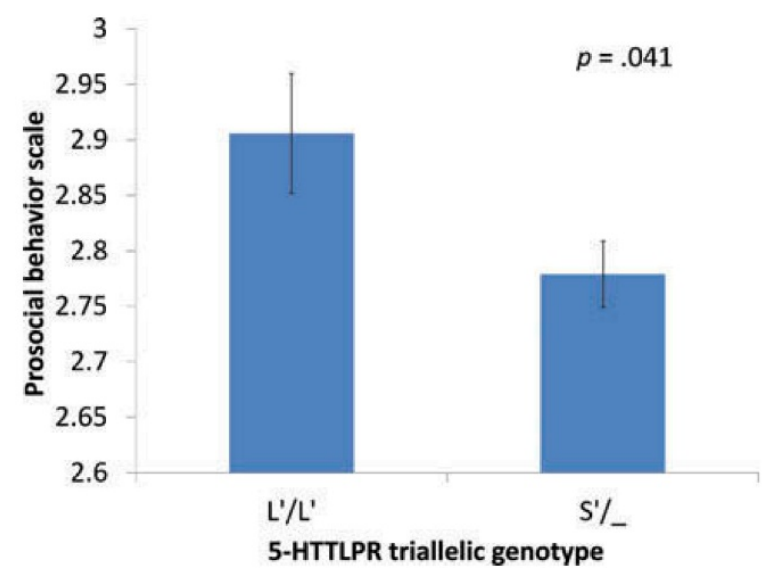

Figure 1. Mean scores on prosocial behavior index for groups defined by 5-HTTLPR triallelic genotype. Higher scores on the prosocial behavior scale indicate higher levels of prosocial behavior. See Supplementary Table S2 for means and standard deviations of prosocial behavior scale scores for groups defined by triallelic 5-HTTLPR genotype in three categories (i.e., L'/L', L'/S', and $\left.S^{\prime} / S^{\prime}\right)$. See Supplementary Table S3 for means and standard deviations of each of the 14 prosocial behavior scale items for groups defined by triallelic 5-HTTLPR genotype in three categories. Error bars indicate \pm 1 SEM.

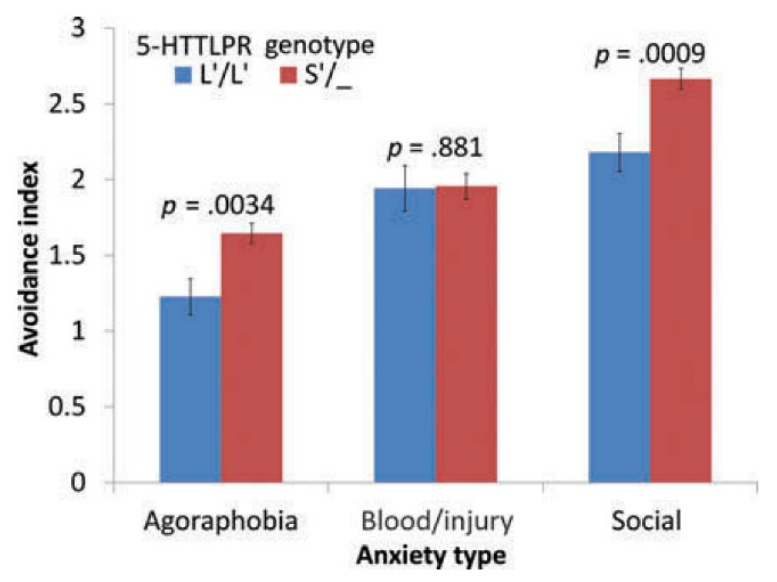

Figure 2. Mean scores on trait anxiety indices for groups defined by 5-HTTLPR triallelic genotype. Higher scores on the avoidance index indicate higher levels of avoidance. See Supplementary Table S2 for means and standard deviations of avoidance index scores for groups defined by triallelic 5-HTTLPR genotype in three categories (i.e., L'/L', L'/S', and $\left.\mathrm{S}^{\prime} / \mathrm{S}^{\prime}\right)$. Error bars indicate \pm 1 SEM.

Results of the mediation tests for social anxiety are shown in Table 2 (results for mediation tests for agoraphobia are similar and shown in Table S1 in the supporting information available online). For the first step in the mediation test, 5-HTTLPR triallelic genotype was regressed on prosocial behavior score. All models included age, gender, and race as covariates. The model including 5-HTTLPR genotype significantly predicted prosocial behavior 
$\left(R^{2} \Delta=.011, F \Delta(1,385)=4.205, p=.041\right)$. In step 2, the model to test whether 5-HTTLPR genotype predicted social anxiety was also significant $\left[R^{2} \Delta=.026, F \Delta(1,388)=11.138, p=.001\right]$. Finally, in step 3 , the effect of 5-HTTLPR on prosocial behavior was reduced $(B=0.085$, $t(384)=1.38, p=.169)$ when social anxiety was included as a predictor, and the model was significant [adj. $\left.R^{2}=.064, R^{2} \Delta=.039, F \Delta(1,384)=15.915, p=.000\right]$. Approximately $33 \%$ of the 5-HTTLPR triallelic genotype effect on prosocial behavior is mediated by social anxiety (Frazier, Tix, \& Barron, 2004).

\begin{tabular}{|c|c|c|c|c|}
\hline Testing steps in mediation model & B & SEB & $95 \% \mathrm{CI}$ & $\mathrm{B}$ \\
\hline \multicolumn{5}{|l|}{ Testing step 1} \\
\hline \multicolumn{5}{|l|}{ Outcome: prosocial behavior } \\
\hline Predictor: 5-HTTLPR genotype & -.127 & .062 & $-.249,-.005$ & $-.104^{*}$ \\
\hline \multicolumn{5}{|l|}{ Testing step 2} \\
\hline \multicolumn{5}{|l|}{ Outcome: social anxiety } \\
\hline Predictor: 5-HTTLPR genotype & .476 & .143 & $.196, .757$ & $.162^{* *}$ \\
\hline \multicolumn{5}{|l|}{ Testing step 3} \\
\hline \multicolumn{5}{|l|}{ Outcome: prosocial behavior } \\
\hline Mediator: social anxiety & -.087 & .022 & $-.129,-.044$ & $-.207^{* * *}$ \\
\hline Predictor: 5-HTTLPR genotype & -.085 & .062 & $-.207, .036$ & -.069 \\
\hline
\end{tabular}

Notes: CI, confidence interval. Covariates tested in each model include age, sex, and race. The pattern of results for the mediation analysis with agoraphobia was similar and is shown in Supplementary Table S1. ${ }^{*} p<.05,{ }^{* *} p<.01,{ }^{* * *} p \leq .001$

\section{Discussion}

This study is the first to test whether the association between genetic variation in the 5-HT system and prosocial behavior is mediated by anxiety. The findings add to the growing evidence that 5-HT system function may influence prosocial behavior and indicate that only certain types of anxiety mediate the association. Individuals homozygous for the high functioning 5-HTTLPR triallelic L' allele had lower mean scores on measures of agoraphobia and social phobia and higher mean scores on a prosocial behavior index than individuals carrying one or two copies of the $S^{\prime}$ allele. Overall, self-reported avoidance of places and social situations was strongly negatively correlated with self-reports of engaging in prosocial behavior. No association was observed between endorsement of blood/injury phobias and either prosocial behavior or 5-HTTLPR genotype. The trait of behavioral inhibition was negatively correlated with prosocial behaviors and positively associated with each type of phobia assessed, most strongly with social phobia. This pattern of results fits well with reinforcer sensitivity theory (Corr \& McNaughton, 2012) and suggests that the inclusion of specific types of behavioral inhibition may further enrich the model. If one considers opportunities to help others as ambiguous and/or risky social situations, the pattern of results observed in the present study is in line with evidence that those carrying one or two $S^{\prime}$ alleles, when compared to individuals homozygous for $L^{\prime}$ alleles, make fewer risky decisions under ambiguity (Stoltenberg et al., 2011), have somewhat hyper-responsive amygdale (Murphy et al., 2012), show enhanced fear conditioning and reduced financial 
risk taking (Crisan et al., 2009), show increased loss aversion (He et al., 2010), have greater levels of emotional reactivity in socially embedded contexts (Gyurak et al., 2013), and are less likely to endorse harming one person to save many (Marsh et al., 2011). These findings together suggest that individuals carrying one or two 5-HTTLPR $S^{\prime}$ alleles experience relatively greater levels of emotional arousal than $\mathrm{L}^{\prime}$ homozygotes and may therefore be less likely to take actions that may carry risk. Our findings are also in line with evidence that negative emotionality is negatively associated with prosocial behavior (Ebstein, Israel, Chew, Zhong, \& Knafo, 2010) and that variation in 5-HTTLPR is associated with anxietylike traits (see Murphy et al., 2008).

Further research is needed to characterize the genetic influences on prosocial behavior and their mediating pathways (Ebstein et al., 2010). A recent study that examined the role of a functional polymorphism in the gene that codes for the enzyme responsible for most catecholamine metabolism (catechol-O-methyltransferase, rs4680) showed that the Met allele is associated with negative emotionality and with lower levels of prosocial behavior (Reuter, Frenzel, Walter, Markett, \& Montag, 2011). Other studies have focused on the well-studied hormone oxytocin that functions as a neuromodulator in the brain, finding that genetic variation in the oxytocin receptor (OXTR) is associated with differences in prosocial decision-making and value orientation (Israel et al., 2009). More candidate gene association studies are needed to replicate extant findings and to examine new candidate genes and other possible mediating pathways.

The present results should be considered in the context of certain limitations of the study design and the population investigated. First, we used only self-report instruments to collect data on aspects of both prosocial behavior and anxiety. Although we used instruments that have been widely used and shown to be reliable, construct validity may be improved by using experimental behavioral measures. Second, our sample was relatively small and racially homogeneous. The pattern of results observed may not generalize to other demographic groups. It should also be noted that pathways from genes to prosocial behaviors cross many levels of analyses and that future work to better characterize these should aim to investigate additional potential mediating factors such as patterns of brain activity (e.g., amygdala) or neuroendocrine responses to stress (e.g., cortisol).

Our findings suggest that carriers of the 5-HTTLPR S' allele are less likely to help others than those who are homozygous for the L' allele. This effect is partially mediated by the tendency to avoid social situations and certain places, but not by avoidance of blood or injury. It may be that $S^{\prime}$ allele carriers have an intense emotional reaction to the uncertainty that accompanies social situations and this manifests in behavioral inhibition, thereby reducing the likelihood of helping. While recent work has focused on the use of oxytocin to enhance prosocial behavior (Yamasue et al., 2012), it remains to be seen whether prosocial behavior can be enhanced by focusing on anxiety reduction for those carrying an $S^{\prime}$ allele of 5-HTTLPR. Moreover, recent scholars have noted the need to distinguish among different forms of prosocial behaviors (e.g., altruistic, compliant, and helping in emergency situations; see Carlo, 2006). Therefore, future research could benefit from studies that investigate the genetic underpinnings of specific forms of prosocial behaviors. 
Acknowledgments - This study was partially funded by a Faculty Research Seed Grant from the UNL Research Council (SFS). Thanks to Amy Proskovec for suggesting the use of the Fear Questionnaire in this study.

\section{References}

Carlo, G. (2006). Care-based and altruistically-based morality. In M. Killen \& J. G. Smetana (Eds.), Handbook of moral development (pp. 551-579). Mahwah, NJ: Lawrence Erlbaum Associates.

Carver, C. S., \& White, T. L. (1994). Behavioral inhibition, behavioral activation, and affective responses to impending reward and punishment: The BIS/BAS scales. Journal of Personality and Social Psychology, 67(2), 319-333.

Cools, R., Nakamura, K., \& Daw, N. D. (2011). Serotonin and dopamine: Unifying affective, activational, and decision functions. Neuropsychopharmacology, 36(1), 98-113.

Corr, P. J., \& McNaughton, N. (2012). Neuroscience and approach/avoidance personality traits: A two stage (valuation-motivation) approach. Neuroscience \& Biobehavioral Reviews, 36(10), 23392354.

Crisan, L. G., Pana, S., Vulturar, R., Heilman, R. M., Szekely, R., Druga, B., . . Miu, A. C. (2009). Genetic contributions of the serotonin transporter to social learning of fear and economic decision making. Social Cognitive and Affect Neuroscience, 4(4), 399-408.

Crockett, M. J. (2009). The neurochemistry of fairness: Clarifying the link between serotonin and prosocial behavior. Annals of the New York Academy of Sciences, 1167, 76-86.

Crockett, M. J., Clark, L., Hauser, M. D., \& Robbins, T. W. (2010). Serotonin selectively influences moral judgment and behavior through effects on harm aversion. Proceedings of the National Academy of Sciences of the United States of America, 107(40), 17433-17438.

Crockett, M. J., Clark, L., \& Robbins, T. W. (2009). Reconciling the role of serotonin in behavioral inhibition and aversion: Acute tryptophan depletion abolishes punishment-induced inhibition in humans. Journal of Neuroscience, 29(38), 11993-11999.

Dayan, P., \& Huys, Q. J. (2008). Serotonin, inhibition, and negative mood. PLoS Computational Biology, 4(2), e4.

Ebstein, R. P., Israel, S., Chew, S. H., Zhong, S., \& Knafo, A. (2010). Genetics of human social behavior. Neuron, 65(6), 831-844.

Eisenberg, N., Fabes, R. A., \& Spinrad, T. L. (2006). Prosocial development. In N. Eisenberg (Ed.), Handbook of child psychology, volume three: Social, emotional and personality development (Vol. 3). Hoboken, NJ: John Wiley \& Sons.

Frazier, P. A., Tix, A. P., \& Barron, K. E. (2004). Testing moderator and mediator effects in counseling psychology research. Journal of Counselor Psychology, 51(1), 115-134.

Gregory, A. M., Light-Hausermann, J. H., Rijsdijk, F., \& Eley, T. C. (2009). Behavioral genetic analyses of prosocial behavior in adolescents. Developmental Science, 12(1), 165-174.

Gyurak, A., Haase, C. M., Sze, J. Goodkind, M. S., Coppola, G., Lane, J., . . Levenson, R. W. (2013). The effect of the serotonin transporter polymorphism (5-HTTLPR) on empathic and self-conscious emotional reactivity. Emotion, 13(1), 25-35.

Hariri, A. R., \& Holmes, A. (2006). Genetics of emotional regulation: The role of the serotonin transporter in neural function. Trends in Cognitive Sciences, 10(4), 182-191.

He, Q., Xue, G., Chen, C., Lu, Z., Dong, Q., Lei, X., . . Bechara, A. (2010). Serotonin transporter genelinked polymorphic region (5-HTTLPR) influences decision making under ambiguity and risk in a large Chinese sample. Neuropharmacology, 59(6), 518-526. 
Ioannidis, J. P., Ntzani, E. E., \& Trikalinos, T. A. (2004). 'Racial' differences in genetic effects for complex diseases. Nature Genetics, 36(12), 1312-1318.

Israel, S., Lerer, E., Shalev, I., Uzefovsky, F., Riebold, M., Laiba, E., . . . Ebstein, R. P. (2009). The oxytocin receptor (OXTR) contributes to prosocial fund allocations in the dictator game and the social value orientations task. PLoS One, 4(5), e5535.

Klucken, T., Alexander, N., Schweckendiek, J., Merz, C. J., Kagerer, S., Osinsky, R., .. Stark, R. (2012). Individual differences in neural correlates of fear conditioning as a function of 5-HTTLPR and stressful life events. Social Cognitive and Affect Neuroscience, 8(3), 318-325.

Leonardo, E. D., \& Hen, R. (2006). Genetics of affective and anxiety disorders. Annual Review of Psychology, 57, 117-137.

Marks, I. M., \& Mathews, A. M. (1979). Brief standard self-rating for phobic patients. Behaviour Research and Therapy, 17, 263-267.

Marsh, A. A., Crowe, S. L., Yu, H. H., Gorodetsky, E. K., Goldman, D., \& Blair, R. J. (2011). Serotonin transporter genotype (5-HTTLPR) predicts utilitarian moral judgments. PLoS One, 6(10), e25148.

Murphy, D. L., Fox, M. A., Timpano, K. R., Moya, P. R., Ren-Patterson, R., Andrews, A. M., . . Wedland, J. R. (2008). How the serotonin story is being rewritten by new gene-based discoveries principally related to SLC6A4, the serotonin transporter gene, which functions to influence all cellular serotonin systems. Neuropharmacology, 55(6), 932-960.

Murphy, S. E., Norbury, R., Godlewska, B. R., Cowen, P. J., Mannie, Z. M., Harmer, C. J., Munafo, M. R. (2012). The effect of the serotonin transporter polymorphism (5-HTTLPR) on amygdala function: A meta-analysis. Molecular Psychiatry, 18(4), 512-520.

Reuter, M., Frenzel, C., Walter, N. T., Markett, S., \& Montag, C. (2011). Investigating the genetic basis of altruism: The role of the COMT Val158Met polymorphism. Social Cognitive and Affect Neuroscience, 6(5), 662-668.

Rushton, P. J., Chrisjohn, R. D., \& Fekken, G. C. (1981). The altruistic personality and the self-report altruism scale. Personality and Individual Differences, 2(4), 293-302. doi:10.1016/0191-8869(81)90084-2s

Seymour, B., Daw, N. D., Roiser, J. P., Dayan, P., \& Dolan, R. (2012). Serotonin selectively modulates reward value in human decision-making. Journal of Neuroscience, 32(17), 5833-5842.

Stoltenberg, S. F., Lehmann, M. K., Anderson, C., Nag, P., \& Anagnopoulos, C. (2011). Serotonin transporter (5-HTTLPR) genotype and childhood trauma are associated with individual differences in decision making. Frontiers in Genetics, 2, 33.

Wendland, J. R., Martin, B. J., Kruse, M. R., Lesch, K. P., \& Murphy, D. L. (2006). Simultaneous genotyping of four functional loci of human SLC6A4, with a reappraisal of 5-HTTLPR and rs25531. Molecular Psychiatry, 11(3), 224-226.

Wood, R. M., Rilling, J. K., Sanfey, A. G., Bhagwagar, Z. \& Rogers, R. D. (2006). Effects of tryptophan depletion on the performance of an iterated prisoner's dilemma game in healthy adults. Neuropsychopharmacology, 31, 1075-1084.

Yamasue, H., Yee, J. R., Hurlemann, R., Rilling, J. K., Chen, F. S., Meyer-Lindenberg, A., \& Tost, H. (2012). Integrative approaches utilizing oxytocin to enhance prosocial behavior: From animal and human social behavior to autistic social dysfunction. Journal of Neuroscience, 32(41), 14109-14117. 
SUPPLEMENTARY TABLE 1

Results of the Hierarchical Regression Analyses to Test Mediation Model

\begin{tabular}{lcccc}
\hline Testing steps in mediation model & $B$ & $S E B$ & $95 \%$ CI & $\beta$ \\
\hline $\begin{array}{l}\text { Testing step 1 } \\
\quad \text { Outcome: Prosocial behavior }\end{array}$ & & & & \\
$\quad$ Predictor: 5-HTTLPR Genotype & -.127 & .062 & $-.249,-.005$ & $-.104^{*}$ \\
Testing Step 2 & & & & \\
$\quad$ Outcome: Agoraphobia & .404 & .137 & $.135, .673$ & $.143^{* *}$ \\
$\quad$ Predictor: 5-HTTLPR Genotype & & & & \\
Testing Step 3 & & & & \\
$\quad \begin{array}{l}\text { Outcome: Prosocial behavior } \\
\text { Mediator: Agoraphobia }\end{array}$ & -.084 & .023 & $-.129,-.039$ & $-.193^{* * *}$ \\
Predictor: 5-HTTLPR Genotype & -.092 & .062 & $-.214, .029$ & -.075 \\
\hline
\end{tabular}

Notes: CI, confidence interval. Covariates tested in each model include age, sex, and race. The pattern of results for the mediation analysis with agoraphobia was similar and is shown in Supplementary Table $\mathrm{S} 1 .^{*} p<.05$, ${ }^{* *} p<.01,{ }^{* * *} p \leq .001$.

SUPPLEMENTARY TABLE 2

Means (standard deviations) of Altruism Scale and types of anxiety as measured by the Fear Questionnaire by three category 5-HTTLPR triallelic genotype

\begin{tabular}{lccc}
\hline Measure & $L^{\prime} / L^{\prime}(n=92)$ & $L^{\prime} / S^{\prime}(n=190)$ & $S^{\prime} / S^{\prime}(n=111)$ \\
\hline Altruism & $2.90(0.53)$ & $2.80(0.51)$ & $2.75(0.52)$ \\
Social Anxiety & $2.24(1.18)$ & $2.62(1.23)$ & $2.67(1.30)$ \\
Agoraphobia & $1.29(1.11)$ & $1.57(1.14)$ & $1.69(1.38)$ \\
Blood Injury Phobia & $1.99(1.49)$ & $1.92(1.48)$ & $2.03(1.46)$ \\
\hline
\end{tabular}

Notes: valid $\mathrm{N}$ for Altruism for $\mathrm{L}^{\prime} / \mathrm{S}^{\prime}=188$ and $\mathrm{S}^{\prime} / \mathrm{S}^{\prime}=110$.

SUPPLEMENTARY TABLE 3

Means (standard deviations) of Altruism Scale items by three category 5-HTTLPR triallelic genotype

\begin{tabular}{|c|c|c|c|}
\hline Item & $L^{\prime} / L^{\prime} n=92$ & $L^{\prime} / S^{\prime} n=190$ & $S^{\prime} / S^{\prime} n=111$ \\
\hline 1. I have given directions to a stranger. & $3.41(0.83)$ & $3.43(0.92)$ & $3.45(0.91)$ \\
\hline 2. I have made change for a stranger. & $2.58(1.20)$ & $2.48(1.20)$ & $2.20(1.03)$ \\
\hline 3. I have given money to a stranger who needed it (or asked me for it). & $2.47(1.18)$ & $2.32(1.06)$ & $2.35(1.09)$ \\
\hline 4. I have donated goods or clothes to a charity. & $3.88(0.88)$ & $3.71(0.86)$ & $3.64(0.94)$ \\
\hline 5. I have done volunteer work for a charity. & $3.98(0.91)$ & $3.64(1.07)$ & $3.54(1.15)$ \\
\hline 6. I have helped carry a stranger's belongings (e.g., books, parcels, etc.). & $2.58(1.10)$ & $2.43(1.05)$ & $2.57(1.02)$ \\
\hline 7. I have delayed an elevator and held the door open for a stranger. & $3.93(0.98)$ & $4.04(0.86)$ & $3.95(0.94)$ \\
\hline $\begin{array}{l}\text { 8. I have allowed someone to go ahead of me in a line (e.g., supermarket, } \\
\text { copying machine, etc.). }\end{array}$ & $3.43(0.86)$ & $3.58(0.86)$ & $3.41(0.87)$ \\
\hline 9. I have given a stranger a lift in my car. & $1.42(0.82)$ & $1.42(0.78)$ & $1.33(0.61)$ \\
\hline $\begin{array}{l}\text { 10. I have let a neighbor whom I didn't know too well borrow an item of some } \\
\text { value (e.g., tools, a dish, etc.). }\end{array}$ & $2.27(1.13)$ & $2.28(1.12)$ & $2.14(1.04)$ \\
\hline $\begin{array}{l}\text { 11. I have bought 'charity' Christmas cards deliberately because I knew it was } \\
\text { for a good cause. }\end{array}$ & $2.22(1.31)$ & $2.02(1.24)$ & $2.00(1.21)$ \\
\hline $\begin{array}{l}\text { 12. I have helped a classmate who I did not know that well with a homework } \\
\text { assignment when my knowledge was greater than his or hers. }\end{array}$ & $3.59(0.90)$ & $3.43(0.88)$ & $3.48(1.00)$ \\
\hline $\begin{array}{l}\text { 13. I have, before being asked, voluntarily looked after a neighbor's pets or } \\
\text { children without being paid for it. }\end{array}$ & $2.64(1.24)$ & $2.47(1.19)$ & $2.38(1.16)$ \\
\hline 14. I have offered to help a handicapped or elderly stranger across a street. & $2.32(1.28)$ & $2.19(1.20)$ & $2.24(1.21)$ \\
\hline
\end{tabular}

Note: Instructions for the Rushton Altruism Scale are as follows: "Below are several different actions in which people sometimes engage. Read each of them and decide how frequently you have carried it out in the past. Blacken in the space on your answer sheet which best describes your past behavior. $1=$ Never, $2=$ once, $3=$ more than once, $4=$ often, $5=$ very often". 